\title{
Teaching Business Demography Using Case Studies
}

\author{
David A. Swanson - Peter A. Morrison
}

Received: 22 June 2009/ Accepted: 25 June 2009/Published online: 29 July 2009

(C) The Author(s) 2009. This article is published with open access at Springerlink.com

\begin{abstract}
Many faculty members consider using case studies but not all end up using them. We provide a brief review of what cases are intended to do and identify three ways in which they can be used. We then use an example to illustrate how we have used the case study method in teaching business demography. Among other benefits, we note that the case studies method not only encourages the acquisition of skills by students, but can be used to promote "deep structure learning," an approach naturally accommodates other features associated with the case studies method-the development of critical thinking skills, the use of real world problems, the emphasis of concepts over mechanics, writing and presentation skills, active cooperative learning and the "worthwhileness" of a course. As noted by others, we understand the limitations of the case study method. However, given its strengths, we believe it has a place in the instructional toolbox for courses in business demography. The fact that courses we teach is a testament to our perceived efficacy of this tool.
\end{abstract}

Keywords Deep structure learning - Historical narrative - Skill acquisition · Decision-making

\section{Introduction}

Although the idea of business demography has been around for at least 25 years (Kintner et al. 1994), pedagogical issues regarding the training of business

D. A. Swanson ( $ه)$

Department of Sociology, University of California, Riverside, CA, USA

e-mail: David.swanson@ucr.edu

P. A. Morrison

RAND, Santa Monica, CA, USA

e-mail: Peterm3636@aol.com 
demographers are only now emerging (Swanson and Pol 2005). As university faculty and others involved in the training of business demographers develop and refine appropriate pedagogical approaches for this task, we suggest that the case study method be taken under consideration. We make this suggestion knowing that while business school faculty are well aware of the case study approach, faculty in social sciences, where most of the training of business and other applied demographers is done, are less aware of it. We also note that our suggestion is not meant to imply that the case study method should be used to the exclusion of other approaches, but that it should constitute one of several tools in the training kit. To help put this in perspective for social science faculty, especially those in sociology (where much of the training of demographers is done), the case study method can be viewed as a 'qualitative technique.'

Like many qualitative methods, a case tells a 'story' that, in turn, can be used in the classroom as a basis for learning (Broder et al. 2003; Patten and Swanson 2003). Case study research, according to Soy (1997), "excels at bringing us to an understanding of a complex issue or object and can extend experience or add strength to what is already known through previous research." A major strength of the case study method is that its focus encompasses richly detailed contexts. Sociologists have long used this approach under the heading "qualitative research" (Feagin et al. 1991). However, this very strength is viewed as the method's major weakness: Critics of the case study method note the difficulty in demonstrating that case study findings are both generalizable and reliable because of the limited "sample size" (Soy 1997). Despite this perceived weakness, the case study method has been used in many fields of study, including, demography and business (Kintner et al. 1994). Although they may extend into fictional realms, cases typically build on real situations in the life of an individual, a profit-seeking company, or a non-profit organization (Feagin et al. 1991). Examples of this approach on topics combining demography and business or demography and government are found in Demographics: A Casebook for Business and Government (Kintner et al. 1994) and academic journals (see, for example, Morrison and Abrahamse 1996; Morrison 1998, 1999). These examples range from market research applications (Billings and Pol 1997) to site selection problems (Thomas 1994).

There is, in addition, an important benefit that appears to accrue from using the case study method terms of "Deep Structure Learning" (Patten and Swanson 2003; Swanson 2005; Swanson and McKibben 1999), which is aimed at the development of critical thinking skills (Roberts 2002; Swanson 2005). Students view it more positively than courses not designed using this approach. Part of this reason may be that the deep structure learning approach naturally accommodates other features associated with the case studies method-the development of critical thinking skills, the use of real world problems, the emphasis of concepts over mechanics, writing and presentation skills, active cooperative learning and the "worthwhileness" of a course (Patten and Swanson 2003; Swanson 2005; Swanson and McKibben 1999).

So, how can cases be used in the classroom? We identify three distinct applications: (1) as an historical narration, (2) as a focal point for acquiring specific skills, or (3) to build decision making skills (Patten and Swanson 2003). After 
Identifying these three applications, we provide a concrete example that is based largely on the third application. ${ }^{1}$

\section{Historical Narration}

Because a case tells a story, it can be used to teach an historical narrative. By this we mean that the student is expected to learn what has happened historically in the life of the entity. Consider a Swiss manufacturing company faced with shrinking demand for its products. The company responds by changing the product design, thereby returning to profitability. The student reading this case learns how the company discovered and described the problem, evaluates the various actions the company contemplated taking, and considers how and why the company finally responded as it did. In using this case study, the instructor has a choice of what to emphasize: (1) analyzing the entire sequence of events; (2) focusing students' attention on the alternatives and how they were formulated; or (3) exploring the actions that returned the company to profitability.

\section{Acquiring Specific Skills}

The second application of cases described in Patten and Swanson (2003) is to enable students to acquire specific skill. The typical format here is a question that the instructor constructs, which students must answer through some research exercise (e.g., a series of calculations, downloading and assembling data). In doing so, the student acquires specific skills by analyzing the question and manipulating relevant data. This approach has the advantage of using a real-life situation, which helps to enliven the learning experience for the student and simultaneously emphasizes the learning experience that the instructor wants to achieve.

To illustrate, assume the faculty member wishes to focus on learning about channels of distribution. A case could be selected that describes a company and the product it manufactures. Information about the cost of manufacturing and the desired profit margin could be provided. The student could then be asked to identify possible ways in which the manufacturer could distribute its product to the consumer. This can be as extensive an analysis as the faculty member decides is appropriate given the level and objectives of the course. Given a certain problem that the case has identified, the student then learns that, she or he must now discover various alternatives to solving the problem. Since the alternatives all must concern distribution channels, the student ends up acquiring a specific skill —in this case, knowledge of how distribution works.

As an example of this approach, here is a brief description of a case approach that hones specific skills used in evaluating global consumer markets using data available from the U.S. Census Bureau and the World Bank. The prospects of rising incomes destined to transform massive populations into rapidly expanding consumer markets spurred a rush of U.S.-based corporations into China, India,

\footnotetext{
${ }^{1}$ Because of space limitations, we are not able to provide the rich details of each of the three types of case studies we describe. These details are available on request from either of the authors.
} 
and other markets during the 1990s. These expanding consumer markets continue to attract corporations whose present-day business derives largely from mature markets with limited prospects for further growth. In their efforts to globalize, corporations need to anticipate the future growth of these emerging consumer markets. Such markets pose distinctive problems amenable to applied demographic analysis. The case centers on a study to refine and expand a corporation's global view of the "middle class" consumer. In this case, the student is called upon to develop data on the preceding points and prepare an analysis to be presented to a client who is contemplating entry into one of several emerging markets and looking for guidance on the comparative demographic strengths and weaknesses of each market.

In this case, the student is called upon to develop data on the above points and prepare an analysis to be presented to a client who is a builder interested in foreseeing future homebuyer preferences. [Data on all of these issues are readily available on the Internet].

\section{Decision Making}

The third instructional application focuses on the art of decision-making. How does one identify problems? What needs to be solved? How does one formulate possible courses of action? What criteria can be used in evaluating solutions or courses of action? Notice that under this approach, the student must discover the problem-it is not identified as such in the case. Not all students will succeed in doing so, but the more discerning ones will lead the discovery process. A case with multiple problems enables the instructor to focus on problem clarification as a key learning outcome. Consequently, this approach is very popular when teaching courses such as strategic management, where it is desirable to encompass the problems involving a variety of subject matter fields. The process of identifying the problem, enumerating possible solutions, establishing criteria to be incorporated in the solution that is selected, and selecting the solution along with the supporting rationale makes for an important experience. Cases are distinctively able to deliver a valuable learning experience in this type of situation. We turn now to a specific example that incorporates the decision-making approach to using cases that illustrates not only the structure of this approach, but also one of many ways in which it can be implemented in the classroom.

\section{An Example of Teaching with the Case Study Method}

The following example was developed by Morrison and extended by Swanson for use in a market demographics course taught for the Helsinki School of Economics. It largely represents the 'decision-making' approach, but it contains elements of skill acquisition. It has the following structure:

1. The Decision-maker: The Decision-maker is the entity responsible for selecting a course of action-making the decision. The decision-maker could be a person, 
or a group of persons, informally or formally constituted. It could also be something designed by people-computer algorithm, for example.

2. The alternative decisions (courses of action): The decision involves selecting one of two or more identified courses of action. The goal is to choose the course of action that is "best."

3. Events: These are occurrences that are beyond the control of the decision-maker but yet can have an effect on the course of action selected. The events are subject to uncertainty but ideally they are mutually exclusive and exhaustive so that one and only one can occur.

4. Return or Payoff: is a measure of net benefit to the decision-maker.

5. Uncertainty: is measured by the probabilities assigned to the identified events. These may be subjective.

The central ideas of the example we use here (as well as Exhibits 1 and 2) are taken from the book, Dealing with Darwin: How Great Companies Innovate at Every Phase of Their Evolution, by Geoffrey A. Moore (2005), for which PowerPoint slides and other materials can be found at the website www.dealingwithdarwin.com. ${ }^{2}$ They are as follows.

(1) A Declining market represents a period in the maturity of a market when, setting aside cyclical fluctuations, growth rates are negative. Strategically, a time to either reinvigorate the category or harvest and exit.

(2) Growth market. A period in the development of a market when growth rates are significantly in excess of $10 \%$. Strategically, a time when gains in market share create more shareholder value than maximizing profits.

(3) Mature market. A period in the development of a market when, setting aside cyclical fluctuations, growth rates are modest, typically less than $10 \%$. Strategically, a time when profits take precedence over revenues and market share.

(4) Now as we enter the latter half of the decade, yet another set of new issues confront us. The great growth market opportunities have been transplanted to Asia and with them local economic advantage as well. Moreover, offers incubated in low-cost economies can be expected to disrupt business models in established markets. How can today's leading enterprises compete successfully for revenues and profits in a globalized, commoditized, deregulated marketplace?

(5) Market (or industry) life cycles describe the evolution of the market. These cycles have a similar shape to the product life cycle and similarly, have three distinct stages:

(a) embryonic-the product class and industry definitions are virtually synonymous, diffusion rates are gradual, and there is considerable uncertainty about the product;

(b) growth-the industry structure develops, the introduction of new product classes becomes easier as consumers become more knowledgeable, and the channels facilitate the marketing of new product classes established; and

\footnotetext{
${ }^{2}$ We thank Geoffrey Moore for giving us permission to use his materials in the classroom and in this paper.
} 


\section{The Category Maturity Life Cycle}

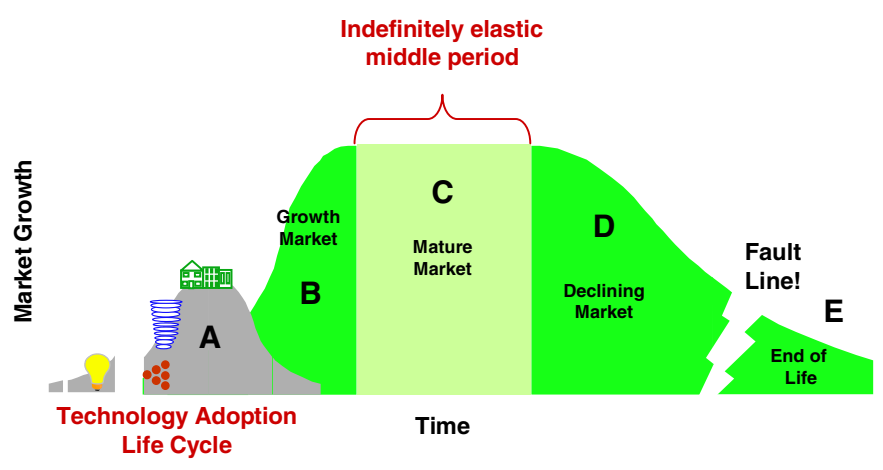

Copyright @ Geoffrey A. Moore, 2005, from the book "DEALING WITH DARWIN"

Exhibit 1 Moore's view of the market life cycle

\section{Core/Context Analysis Framework}

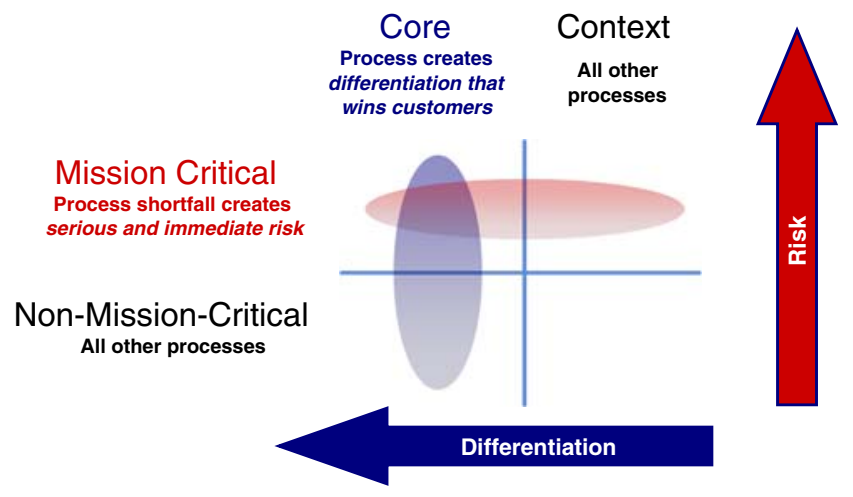

Copyright $\odot$ Geoffrey A. Moore, 2005, from the book "DEALING WITH DARWIN"

Exhibit 2 Moore's analytic framework

(c) maturity and established infrastructure facilitates rapid introduction and diffusion of new product variants or product classes, competitors jockey for position, and older products have to make adjustments to protect their declining position." 
The preceding concepts are summarized in Moore's (2005) view of the Market Life Cycle, as shown in Exhibit 1.

To add more of the information you need to see how this works, we continue with the critical concepts Geoffrey Moore (2005) overlays on the market life cycle, "Context," "Core," and "Core/Context analysis." It is the latter the case study is aimed at getting the students to process and understand.

Context. Any activity which does not differentiate the company from the customers' viewpoint in the target market. Context management seeks to meet (but not exceed) appropriate accepted standards in as productive a manner as possible.

Core. Any activity which creates sustainable differentiation in the target market resulting in premium prices or increased volume. Core management seeks to dramatically outperform all competitors within the domain of core.

Core/context analysis. A resource prioritization framework that discriminated differentiating processes from all other work. Core/context management advocates funding differentiating initiatives in growth markets by extracting resources (carefully) from mission-critical context initiatives in mature markets.

The preceding concepts are summarized in an analytic framework, as shown in Exhibit 2.

The implementation of Moore's ideas in terms of an actual case study used in a business demography class uses real data derived from Billings and Pol (1994), under the pseudonym, "Weasel Cellular, Inc.," a company "providing cell phone service in the United States." Students are told that the company has recently adopted the perspective of Geoffrey Moore to analyze its existing and potential market and that each of them is a finalist for a position as a market research analyst at Weasel Cellular. The students have been informed that they have made it through the initial screening and a series of interviews and are now being given a test to see how well they understand the market life cycle and related concepts developed by Geoffrey Moore that they claimed to have knowledge of in their resumes and interviews. The test consists of conducting a "Core/Context Analysis" using the data contained in Tables 1, 2, 3, and 4, which provide information at two points in time ("now" and 10 years in the future) for two hypothetical counties in Florida (K and $\mathrm{S}$ ) on cellular phone subscriptions by age, people by age, and "market attractiveness index" by age.

In the test, students are asked to examine the information for these two counties from the perspective of a high level executive in Weasel Cellular and determine which of the two should be considered as "core" and which one should be considered as "context." A key issue here is how the students view the changing demographics in the two counties. Should they focus more on size, on the agedistribution, or try to achieve a balance between the two? Whichever of these characteristics they choose, the students are required to provide a justification for their determinations in the form of memos. Exhibits 3 and 4 provide responses from two students, "A," and "B," to the "test" comprising this case study. The two students both used a demographic perspective to come up with a recommendation, but their recommendations are very different. As you read through these two exhibits, keep in mind not only that the demographic and related analyses are well- 
Table 1 Current population by age (number and percent) in county $\mathrm{K}$ and county $\mathrm{S}$

\begin{tabular}{lccccc}
\hline Age & \multicolumn{2}{l}{ County $\mathrm{K}$} & & \multicolumn{2}{l}{ County S } \\
\cline { 2 - 3 } \cline { 5 - 6 } & Number & Percent $(\%)$ & & Number & Percent (\%) \\
\hline Less than 25 & 229505 & 40 & 57442 & 23 \\
$25-34$ & 97209 & 17 & 27731 & 11 \\
$35-44$ & 70750 & 12 & 24512 & 10 \\
$45-54$ & 58095 & 10 & 22532 & 9 \\
$55-64$ & 57520 & 10 & & 40359 & 16 \\
65 and over & 62121 & 11 & 75024 & 31 \\
Total & 575200 & 100 & 247600 & 100 \\
\hline
\end{tabular}

Table 2 Current cellular phone subscriptions (\%) by age, population by age (\%), and market attractiveness index (\% subscriptions $\times \%$ age) by age: county $\mathrm{K}$ and county $\mathrm{S}$

\begin{tabular}{|c|c|c|c|c|c|c|}
\hline \multirow[t]{2}{*}{ Age } & \multicolumn{3}{|l|}{ County K } & \multicolumn{3}{|l|}{ County S } \\
\hline & Subscriptions (\%) & Population (\%) & Index & Subscriptions (\%) & Population (\%) & Index \\
\hline Less than 25 & 3 & 40 & 120 & 3 & 23 & 69 \\
\hline $25-34$ & 29 & 17 & 493 & 29 & 11 & 319 \\
\hline $35-44$ & 39 & 12 & 468 & 39 & 10 & 390 \\
\hline $45-54$ & 20 & 10 & 200 & 20 & 9 & 180 \\
\hline $55-64$ & 7 & 10 & 70 & 7 & 16 & 112 \\
\hline 65 and over & 2 & 11 & 22 & 2 & 31 & 62 \\
\hline Total & 100 & & 1373 & 100 & & 1132 \\
\hline
\end{tabular}

The market attractiveness index is found by multiplying the percent of total subscriptions at a given age group by the percent of the total population in this same age group

Table 3 Forecasted population 10 years from now by age (number and percent) in county K and county S

\begin{tabular}{lccccc}
\hline Age & \multicolumn{2}{l}{ County $\mathrm{K}$} & & \multicolumn{2}{l}{ County $\mathrm{r}$} \\
\cline { 2 - 3 } \cline { 5 - 6 } & Number & Percent (\%) & & Number & Percent (\%) \\
\hline Less than 25 & 217000 & 35 & 76000 & 20 \\
$25-34$ & 99200 & 16 & & 34200 & 9 \\
$35-44$ & 68200 & 11 & 38000 & 10 \\
$45-54$ & 68200 & 11 & & 38000 & 10 \\
$55-64$ & 68200 & 11 & & 64600 & 17 \\
65 and over & 99200 & 16 & & 129200 & 34 \\
Total & 620000 & 100 & 380000 & 100 \\
\hline
\end{tabular}


Table 4 Forecasted cellular phone subscriptions 10 years from now (\%) by age, population by age (\%), and market attractiveness index ( $\%$ subscriptions $\times \%$ age) by age: county $\mathrm{K}$ and county $\mathrm{S}$

\begin{tabular}{|c|c|c|c|c|c|c|}
\hline \multirow[t]{2}{*}{ Age } & \multicolumn{3}{|l|}{ County K } & \multicolumn{3}{|l|}{ County S } \\
\hline & Subscriptions (\%) & Population (\%) & Index & Subscriptions (\%) & Population (\%) & Index \\
\hline Less than 25 & 2 & 35 & 70 & 2 & 20 & 40 \\
\hline $25-34$ & 15 & 16 & 240 & 15 & 9 & 135 \\
\hline $35-44$ & 18 & 11 & 198 & 18 & 10 & 180 \\
\hline $45-54$ & 27 & 11 & 297 & 27 & 10 & 270 \\
\hline $55-64$ & 23 & 11 & 253 & 23 & 17 & 391 \\
\hline 65 and over & 15 & 16 & 240 & 15 & 34 & 510 \\
\hline Total & 100 & & 1298 & 100 & & 1526 \\
\hline
\end{tabular}

The market attractiveness index is found by multiplying the percent of total subscriptions at a given age group by the percent of the total population in this same age group

The purpose of this memo is to demonstrate my analytical skills as a part of my job interview. To do this, I will conduct a core/context analysis on Weasel Inc's current market situation as well as the projected values for the year 2017.

As Table 2 of the data given to me demonstrates, Weasel Inc is currently making more profit in $\mathrm{K}$ than in $\mathrm{S}$, as the total Market Attractiveness Index in K is 1373 and in S 1132. This is understandable, seeing as the population of K $(575,200)$ is more than twice the population of S $(247,600)$. Currently the group of people aged between 25 and 34 in $\mathrm{K}$ has got the highest Market Attractiveness Index overall (493), which means that it brings in more profit than any other single group.

The most notable difference between $\mathrm{K}$ and $\mathrm{S}$ in terms of population is that people in $\mathrm{K}$ are fairly young, while people in $\mathrm{S}$ are much older than average. In all of the United States, the percentage of people over the age of 65 is 12.1 (source: US Census Bureau, S0101, Age and Sex), while in K it is 31. Additionally, the national average for people under the age of 25 is 41.2 per cent, while in $\mathrm{K}$ it is currently only 23 per cent.

In ten years' time, as shown by Table 4, the percentage of people over the age of 55 that have subscribed to Weasel Inc is expected to have multiplied. This explains why, even though S remains the smaller county, by 2017 Weasel will be making more profit in S than in K. By then, with the Market Attractiveness Index of 510, people over 65 in $\mathrm{S}$ will be the biggest single group to bring in money to Weasel Inc.

Considering that S, despite being much smaller, will in ten years be more valuable a market to Weasel than K, I would focus on $\mathrm{S}$ as the core and $\mathrm{K}$ as the context. The age groups of people over 55 are about to enter the mission-critical deployment zone where resources are very much needed in order to succeed in creating a mature market.

Additionally, the number of subscriptions among people aged 25 to 34 and 35 to 44 is expected to drop in the next ten years. Currently they make up for 68 per cent of all subscriptions, but ten years from now the number is expected to be merely 23 per cent. It is clear that this is a declining market.

Therefore, if I was an executive director for Weasel Inc, I would allocate some resources from these age groups to older groups by for instance retargeting the promotion of the products. This works in accordance to Geoffrey Moore's Core/Context Analysis and is supported by the Cycle of Innovation (source: Dealing with Darwin, The Cycle of Innovation), where resources are taken from declining markets and re-invested in new innovations or products in the growing deployment zone.

Finally, it is noteworthy that S will not be endlessly more profitable than K. In 2017, an entire 51 per cent of people in $\mathrm{S}$ will be 55 or older while in $\mathrm{K}$ the same number is only 27 per cent. However, in the following years, there are more people in $\mathrm{K}$ who will enter this age group than there are in $\mathrm{S}$. These factors should be taken into consideration when conducting new market analyses in the future

Exhibit 3 Response from student "A"

considered and justified by the two students, but also that they are upper division undergraduates who are non-native English speakers.

We believe that these two examples (selected randomly from the entire set) not only illustrate the points we have made earlier about the acquisition of demographic and related analytic skills, but also a point we again turn to at the end of this paperthe development of critical thinking skills. 
Geoffrey Moore's Market life cycle describes the overall evolution of a market which goes through four different stages that are embryonic, growth, maturity and decline. In the first quadrant new ideas are developed, there for it is called the innovation stage. In second quadrant implementation of the idea is put into action. This stage is also the point in the life cycle where the market is growing and it has not yet reached its peak. These first two phases are considered as core in the core/context analysis. The core is any activity which creates sustainable differentiation in the target market resulting in premium prices or increased volume (G. Moore, Dealing with Darwin). Quadrant 3 is called manage and it is where the market is mature. It is indefinitely elastic middle period where the market is in its "cash cow" stage. Finally at the fourth and the final stage the market life cycle curve declines. From this quadrant resources are extracted to fund new innovations. Phases 3 and 4 are context part of the analysis. Context is any activity which does not differentiate the company from the customers' viewpoint in the target market (G. Moore, Dealing with Darwin).

The cellular phone industry in the U.S. has developed quite slowly but it is growing steadily, hence I consider it to be in the stage two of the market life cycle. According to data provided in table 1, County K's $(\mathrm{K})$ population structure is considerably younger than in county $\mathrm{S}(\mathrm{S})$ since over half of the population is under 35 years old. Contrary in $\mathrm{S}$ more than half of the population is over 45 years old. Overall $\mathrm{K}$ has twice the population compared to $\mathrm{S}$.

Table 2 shows the current cellular phone subscriptions and market attractiveness index (MAI) which demonstrates the relative measure of expected revenue production in comparison. In $\mathrm{K}$ the index is much higher (1373) than in S (1132) and therefore market in $\mathrm{K}$ is currently more valuable market area for Weasel Cellular, Inc. MAI shows that age groups 25-44 are the main consumers in both counties. Because of K's bigger number of younger generation groups the index is higher than in S.

Based on the information data in these fist two tables I would consider $\mathrm{K}$ as a core and $\mathrm{S}$ as a context. Therefore the current information would suggest Weasel Cellular, Inc. to concentrate more in area $\mathrm{K}$.

When looking at forecasted population 10 years from now by age in table 3, it shows that $\mathrm{S}$ has grown much more than $\mathrm{K}$ (growth rates for S: $53.5 \%$ and for $\mathrm{K}: 7.8 \%$ ). The population in general has grown older and the percentage value for groups under 35 have decreased in both counties. Due to the changes in the population age structures the table 4 shows that after ten years from now the MAI is higher in S than it is in K. Now it can be seen that the current situation will be reversed. Statically K's index has decreased by $5.5 \%$ while S's has increased by $34.8 \%$ based on my calculations.

The predicted trend of subscriptions has shifted in favor of people over the age of 45 vice versa to the current situation in which younger people are the main consumers. Reasons for this change could be that since the cellular phone is quite a new product now, it is used by fairly young consumers because this group is more keen on using new products. However, in the future I assume that there will be new innovations and products on the market that are adapted by new youngsters. Today's main user groups will get older but most likely remain as cellular phone users and thus possible consumers for Weasel Cellular, Inc.

When the situation is applied to the Moore's market lifecycle, $\mathrm{K}$ is currently placed in the second quadrant being a core function, while $\mathrm{S}$ is context. At the moment it seems to be that $\mathrm{K}$ is a more mission critical than $\mathrm{S}$ although $\mathrm{S}$ is also producing steady revenue. Right now one can invest money in deploying $\mathrm{K}$ for getting the maximized profits. However, knowing the future forecasted indexes, I would recommend that the company would start to concentrate on S more than on K. In the future S will turn to a core function because of S's higher expected revenue production. This can be explained by S's more rapidly increasing population and more favorable consumer population.

As a conclusion I recommend that Weasel Cellular, Inc. should place S as their core market and this way be able to answer future market demand. As K's MAI will be decreasing, it will not be as profitable as it is now. Hence it should be considered as context market. S will become more mission critical in the future requiring more resources. The company should invest in county $\mathrm{S}$ in the future.

Exhibit 4 Response from student "B"

\section{Concluding Remarks}

As can be seen from the discussion and the example, there are particular features of the case study method that are appealing, both to students and to instructors. A major feature is that case studies support using "a real-world" scenario. That is, a scenario that uses real data in the context of grappling with an open ended problem. The fact that this can be nicely handled in group work also is appealing (Penn State 2002). Besides acquiring skills, the fact that cases can be used to illustrate and understand decision-making, means that case studies can be used to promote "Deep Structure Learning," a learning outcome we have advocated elsewhere (Swanson 2005; Swanson and McKibben 1999). ${ }^{3}$

\footnotetext{
3 "Deep structure learning" is a term developed by Keith Roberts (2002). Using a framework developed by Patricia King and Karen Kitchener (1994), Roberts views the development of critical thinking as a progression that starts with a stage labeled "pre-reflective thinking," moves to "quasi-reflective thinking", and culminates in the third and final stage, "reflective thinking." King and Kitchener (1994) describe the final stage of the process - reflective thinking - as the ability to reason about unstructured questions that have no absolute answers.
} 
As noted at the start of this paper, there is, in addition, an important benefit that appears to accrue from using the case studies method in conjunction with the goal of Deep Structure Learning: Students view it more positively than courses not designed using it (Patten and Swanson 2003; Swanson 2005; Swanson and McKibben 1999). Part of this reason may be that the deep structure learning approach naturally accommodates other features associated with the case studies method - the development of critical thinking skills, the use of real world problems, the emphasis of concepts over mechanics, writing and presentation skills, active cooperative learning and the "worthwhileness" of a course (Patten and Swanson 2003; Swanson 2005; Swanson and McKibben 1999).

The skills acquired by students in conjunction with this case study are largely conceptual in that they become sensitized to issues involving population size and composition, as can be seen in Exhibits 3 and 4. They also develop an appreciation for the components of population change because the case study involves examining populations over time.

In conclusion, while we recognize the limitations of the case study method (Soy 1997), we believe it as a place in the instructional toolbox for training business demographers. One important benefit for social science faculty is that a case study can be used in isolation or as part of an overall teaching strategy. For our part, we tend to use a series of case studies in courses we have taught, such that all three approaches are covered-historical narration, skill acquisition, and decisionmaking. The fact that we use cases in business demography (and other) courses we teach is a testament to our perception of the efficacy of this tool. ${ }^{4}$

Acknowledgements The authors are grateful for comments made by Farhat Yusuf and anonymous reviewers.

Open Access This article is distributed under the terms of the Creative Commons Attribution Noncommercial License which permits any noncommercial use, distribution, and reproduction in any medium, provided the original author(s) and source are credited.

\section{References}

Billings, G., \& Pol, L. (1994). Improving cellular market area valuation with demographic data. In H. Kintner, T. Merrick, P. Morrison, \& P. Voss (Eds.), Demographics: A casebook for business and government (pp. 93-108). Santa Monica, CA: RAND.

Broder, J., Klein, H., Martin, R., Rosenbloom, A., \& Zufan, P. (2003). An international survey of case use in higher education: Report of the WACRA case standard setting committee. In H. Klein (Ed.), Case method research and application: Interactive, innovative teaching and training, including distance and continuing education, case method, and other techniques (pp. 3-12). Madison, WI: The World Association for Case Method Research and Application.

Feagin, J., Orum, A., \& Sjoberg, G. (Eds.). (1991). A case for the case study. Chapel Hill, NC: The University of North Carolina Press.

King, P., \& Kitchener, K. (1994). Developing reflective thinking: Understanding and promoting intellectual growth and critical thinking in adolescents and adults. San Francisco, CA: Jossey-Bass.

\footnotetext{
${ }^{4}$ Syllabi and class materials for courses that use case studies can be obtained from either of the two authors.
} 
Kintner, P., Merrick, T., Morrison, P., \& Voss, P. (Eds.). (1994). Demographics: A casebook for business and government. Santa Monica, CA: RAND.

Moore, G. (2005). Dealing with Darwin: How great companies innovate at every phase of their evolution. New York, NY: Penguin.

Morrison, P. (1998). Applying demographic analysis in affirmative action disputes: An instructional case. Population Research and Policy Review, 17(5), 457-478.

Morrison, P. (1999). Unveiling the demographic 'action' in class action law suites: Two instructional cases. Population Research and Policy Review, 18(5), 489-503.

Morrison, P., \& Abrahamse, A. (1996). Applying demographic analysis to store site selection. Population Research and Policy Review, 15(5-6), 479-489.

Patten, R., \& Swanson, D. (2003). Using cases in the teaching of statistics. In H. E. Klein (Ed.), Interactive innovative teaching and training: Case method and other techniques (pp. 21-30). Needham, MA: World Association for Case Method Research \& Applications.

Penn State. (2002). Using cases in teaching. Teaching and learning with technology website. http://tlt.its.psu.edu/suggestions/cases. Accessed December, 2002.

Roberts, K. (2002). Ironies of effective teaching: Deep structure learning and constructions of the classroom. Teaching Sociology, 30 (January), 1-25.

Soy, S. (1997). The case study as a research method. Unpublished Paper. University of Texas Austin. http://fiat.gslis.utexas.edu ssoy/useusers/1391d1b.htm. Accessed June, 2009.

Swanson, D. (2005). Deep structure learning and statistical literacy. Delta Education Journal, 3(1), 4152.

Swanson, D., \& McKibben, J. (1999). Teaching statistics to non-specialists: A course aimed at increasing both learning and retention (pp. 159-166). In L. Pereira-Mondoza, L. Kea, T. Kee, \& W. Wong (Eds.), Statistical education-expanding the network: Proceedings of the fifth international conference on teaching statistics. International Association for Statistical Education, International Statistical Institute, Voorburg, Netherlands.

Swanson, D., \& Pol, L. (2005). Contemporary developments in applied demography within the United States. Journal of Applied Sociology, 21(2), 26-56.

Thomas, R. (1994). Using demographic analysis in health service planning: A case study in obstetrical services. In H. Kintner, T. Merrick, P. Morrison, \& P. Voss (Eds.), Demographics: A casebook for business and government (pp. 159-179). Santa Monica, CA: RAND. 